Article category: Translational Science

\title{
Symptom burden and information needs in prostate cancer survivors: A case for tailored long-term survivorship care
}

Jennifer K. Bernat ${ }^{1}$, Daniela A. Wittmann ${ }^{2}$, Sarah T. Hawley ${ }^{2}$, Daniel A. Hamstra $^{2}$, Alexander M. Helfand ${ }^{2}$, David A. Haggstrom ${ }^{1}$, May Darwish-Yassine ${ }^{3}$, Ted A. Skolarus ${ }^{2,4}$

${ }^{1}$ Indiana University, Indianapolis, IN; ${ }^{2}$ University of Michigan, Ann Arbor, $\mathrm{Ml} ;{ }^{3}$ Michigan Public Health Institute, ${ }^{4}$ VA HSR\&D Center for Clinical Management Research, VA Ann Arbor Healthcare System, Ann Arbor, MI

\section{Corresponding Author:}

Ted A. Skolarus, MD, MPH

Assistant Professor of Urology

Department of Urology, University of Michigan

VA HSR\&D Center for Clinical Management Research

VA Ann Arbor Healthcare System

Phone: (734) 936-0054

Fax: (734) 232-2400

tskolar@med.umich.edu

Keywords: survivorship; quality; information needs; tailoring; self-management

Manuscript word count: 2425 (217 abstract)

\section{Figures: 1}

\section{Tables: 3}

This is the author manuscript accepted for publication and has undergone full peer review but has not been through the copyediting, typesetting, pagination and proofreading process, which may lead to differences between this version and the Version of Record. Please cite this article as doi: 10.1111/bju.13329

This article is protected by copyright. All rights reserved 
References: 28

Pages: 15
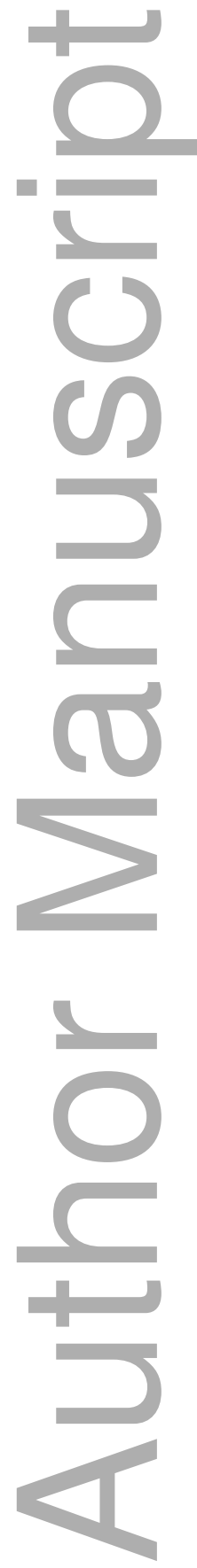

This article is protected by copyright. All rights reserved 
Received Date : 14-Jul-2015

Revised Date : 02-Sep-2015

Accepted Date : 08-Sep-2015

Article type : Original Article

Article category: Translational Science

\begin{abstract}
Objectives: To determine the relationship between long-term prostate cancer survivors' symptom burden and information needs.

Subjects/patients and methods: We used population-based data from the Michigan Prostate Cancer Survivor Study $(n=2,499)$. We examined unadjusted differences in long-term information needs according to symptom burden and performed multivariable logistic regression to examine symptom burden and information needs adjusting for patient characteristics.

Results: High symptom burden was reported across all domains (sexual 44.4\%, urinary 14.4\%, vitality $12.7 \%$, bowel $8.4 \%$, emotional $7.6 \%$ ) with over half of respondents (56\%) reporting they needed more information. Top information needs involved recurrence, relationships, and long-term effects. Prostate cancer survivors with high symptom burden more often searched for information regardless of domain $(p<0.05)$. High sexual burden was associated with greater need for information about relationships $(O R=2.05 ; 95 \%$ CI 1.54-2.72) and long-term effects (OR=1.60; 95\% CI 1.23-2.07). High bowel burden was associated with greater information need for long-term effects (OR=2.28; 95\% CI 1.43-3.63).

Conclusions: Long-term prostate cancer survivors with high symptom burden need more supportive information. Tailoring information to these needs may be an efficient approach to support the growing population of long-term prostate cancer survivors.
\end{abstract}

\title{
Introduction
}

There are more than one million new prostate cancer diagnoses each year resulting in millions of prostate cancer survivors around the globe $(1,2)$ with reduced quality of life due to treatment-related symptoms. (3-5) Treatment type and satisfaction with treatment have distinct impacts on quality of life domains (e.g., urinary, sexual, bowel, emotional, vitality). (4) In addition, prostate cancer survivors may be "lost in transition" between active treatment and survivorship care leaving them vulnerable to persistent, untreated symptoms. (6) While the number of survivors continues to 
increase, the lack of consensus as to who is responsible for follow-up care (primary care clinicians, urologists) increases the risk of persistent symptom burden. (7-10)

Plans for improved survivorship care are being developed and implemented, including the recent American Cancer Society guidelines for prostate cancer survivorship care. (11) These guidelines can support primary care clinicians in providing long-term prostate cancer survivorship care. However, even when prostate cancer symptom burden is high, men may still not report urinary complaints and sexual dysfunction to their primary or specialty care clinicians. In some cases, clinicians may feel uncomfortable or ill equipped to handle these sensitive topics. $(12,13)$ As such, prostate cancer survivors may engage in symptom self-management by seeking health information, and then, caring for themselves. For cancer patients in general, having the appropriate amount of cancer-relevant information from a variety of sources improves patient outcomes across the cancer control continuum. $(14,15)$ Information not only improves shared decision-making about treatment, $(16,17)$ but aids in coping and reducing stress $(15,18,19)$ and may improve overall satisfaction with treatment outcomes. (20)

There are differing information needs and seeking behaviors throughout the trajectory of treatment and survivorship for men with prostate cancer. (21) Most studies examine information needs immediately after treatment and during the initial years of survivorship rather than examining needs later in the survivorship experience when many men may continue to struggle with symptoms. Due to the natural history of prostate cancer, survivors are likely to need ongoing supportive care and information when it comes to treatment side effects and symptom management. $(12,22,23)(24-26)$ Moreover, evidence suggests that tailoring cancer-specific and self-management information to the stage of cancer control continuum (e.g., diagnosis, treatment, posttreatment) most appropriately meets survivors' needs. (14) The additional benefit of extending this tailored information paradigm to a prostate cancer survivor's long-term symptom burden is under studied, and better understanding the relationship between symptom burden and information needs may help identify the most efficient ways to support the growing population of prostate cancer survivors (i.e., focusing on those with the highest symptom burdens). 
The objective of this study was to determine if survivors' domain-specific symptom burden was associated with increased long-term information needs. We also sought to determine additional patient characteristics (e.g., race, treatment type) that may be associated with increased information needs. This analysis focused on symptom burden and information needs for two reasons. First, long-term symptom burden is a documented problem in prostate cancer survivors, many of whom do not seek care for their symptoms. (12) Second, data suggest that prostate cancer survivors need more information about a variety of topics, including symptom management and coping. $(12,22,23)$ Individualized approaches are not typically feasible in health care systems due to resource constraints. As such, our analysis identified factors (e.g., high sexual burden) to consider for more efficient information tailoring (e.g., relationship advice).

\section{Subjects/patients and methods}

Study population

We used data from the Michigan Prostate Cancer Survivor Study, a statewide survey of long-term prostate cancer survivor outcomes (see original study for detailed methods). (12) Individuals diagnosed with prostate cancer in Michigan between 1985 and 2004 and alive as of December 31, 2005 were identified from the Michigan Cancer Registry. Stratified random sampling was conducted to ensure adequate inclusion of prostate cancer survivors based on race/ethnicity, residence (urban versus rural), and number of years since diagnosis. African Americans were oversampled due to their increased prostate cancer risks. Exclusion criteria included: unconfirmed cancer, incarceration, inability to locate, non-resident of Michigan, unable to complete the survey, and physician recommendation against patient contact. Surveys were mailed to eligible participants $(n=6,531)$, and to maximize response rates, up to two follow-up surveys (every six weeks) were mailed to non-respondents. Our final response rate was $38.3 \%$ (2,499 surveys completed). Demographic and treatment factors (age, race, marital status, income, education level, years since diagnosis, treatment type, and disease status) were collected through self-reporting.

Symptom burden 
To measure prostate cancer survivors' symptom burden, we focused on responses to a single domain-specific survey item that captured burden over the prior four-week period. These domains and single-item questions were taken from the Expanded Prostate Cancer Index Composite-26 (EPIC-26) for use in the survey. For each domain (urinary, sexual, bowel, vitality) and an additional emotional domain, respondents were asked, "Overall, how much of a problem, if any, have urinary (sexual, bowel, vitality, emotional) symptoms been for you during the past 4 weeks?" Participants indicated their level of burden on a 5-point scale (no problem, very small problem, small problem, moderate problem, big problem). For each domain, we split the participants into low and high symptom burden groups by placing those participants with moderate or big problems into the high symptom burden group and the rest into the low symptom burden group. Additionally, we conducted a sensitivity analysis by splitting the participants into low and high symptom burden groups using median splits within each domain. For some domains (bowel, vitality, emotional), the median score was 1 , indicating "no problem." We determined that using the moderate to big problem cutoffs (instead of median splits) resulted in a more conservative grouping method. The language used in the survey (face validity) captured those who were truly burdened; thus, this was the method used for subsequent analyses.

\section{Information needs}

We were interested in identifying the primary areas of information need to describe topics that could be addressed during clinical encounters with prostate cancer survivors, and the extent to which these needs were associated with symptom burden. We assessed information needs by asking: "Which areas of prostate cancer-related information do you feel that you need more complete information on? Check all that apply." Respondents selected topics from the following list of common survivorshiprelated information needs: Information on prostate cancer in general; Causes of cancer/prevention of cancer; Diagnosis of cancer; Long-term effects/recovery from cancer; Symptoms of cancer; Where to get medical care; Effect of cancer on my spouse or partner; Recurrence of prostate cancer; Cancer organizations; Coping with cancer/dealing with cancer; Paying for medical care/insurance; Screening/testing/early 
detection; Treatment/cures for cancer; Alternative/home remedies; Effect of cancer on my marital relationship; Other (please specify); None.

\section{Statistical analysis}

We used descriptive statistics to describe our study population and included the following variables: age, race, education level, marital status, income, time since diagnosis, treatment type, and low/high domain-specific symptom burden (urinary, sexual, bowel, vitality, emotional). We also examined the percentage of patients reporting specific cancer survivorship-related information needs to identify the most common topics that providers might need to address. Next, we assessed the adjusted differences in information need according to domain-specific symptom burden using chisquare tests with Bonferroni corrections. Last, we used multivariable logistic regression to examine the association between high symptom burden and the most common reported survivorship-related information need topics (recurrence, relationship effects, and long-term effects) adjusting for patient characteristics.

Research approval was granted by the Michigan Public Health Institute (MPHI) and the Michigan Department of Community Health (MDCH) Institutional Review Boards, the MPHI privacy officer, and the MDCH Scientific Advisory Panel. All analyses were conducted using SPSS ${ }^{\mathrm{TM}}$ software version 22.

\section{Results}

There were 2,499 respondents (Table 1) who were a median of 9 years from diagnosis (IQR=7) with a median age of 76 years. Nearly $20 \%$ identified themselves as non-white. The majority was married $(78.4 \%)$ and had some level of college education $(59.8 \%)$, with median income ranging from $\$ 35,000$ - $\$ 49,999$. Of those who received treatment, the majority underwent prostatectomy alone (55.1\%). A few respondents $(12.3 \%)$ reported having a recurrence. We found differences in the degree of symptom burden across quality of life domains, with the sexual domain having largest group of highly burdened men (high sexual burden $44.4 \%$ ), followed by urinary (14.4\%), vitality (12.7\%), bowel (8.4\%), and emotional domains $(7.6 \%)$.

We found that $56 \%$ of respondents reported needing more complete cancer survivorship information. The leading information needs related to recurrence of prostate cancer (55.5\%), effects on spouse/relationship (50.2\%), and long term 
effects/recovery from cancer (44.5\%) (Table 2). The least information was sought for 'other' $(4.9 \%)$ and for cancer organizations $(5.5 \%)$. When stratifying by symptom burden level and domain, individuals with high symptom burden compared to low symptom burden were more likely to need more information on at least one of the leading topics (i.e., recurrence of prostate cancer, effects on spouse/relationship, and long term effects/recovery from cancer) regardless of the specific domain (Figure 1). There was a strong association between a need for information regarding the identified topics and the degree of symptom burden across all five domains: urinary, bowel, sexual, emotional, and vitality (all $\mathrm{p}<0.05$ ). Needing more information about long-term effects/recovery from cancer was significantly associated with high symptom burden across all domains $(p<0.001)$. Additionally, needing more information about recurrence of prostate cancer and effects on spouse/relationship varied across urinary $(p=0.007$, $p=0.03)$, sexual $(p=0.004, p<0.001)$, vitality $(p=0.01, p<0.001)$, and emotional domains $(p=0.06, p<0.001)$. The difference in information needs with regard to prostate cancer recurrence and the impact on spouse/relationships was not significant for those with high versus low bowel symptoms $(p=0.15 ; p=0.20)$.

We then examined the association between demographic and treatment factors, including symptom burden, and information needs (Table 3). Factors associated with greater information needs about recurrence of prostate cancer included non-white race (Odds Ratio (OR)=1.36; 95\% Confidence Interval $(\mathrm{Cl})$ 1.00-1.85), having higher income $(\mathrm{OR}=1.72,95 \% \mathrm{Cl} 1.03-2.87)$, and undergoing a combination of treatments for prostate cancer ( $\mathrm{OR}=1.79,95 \% \mathrm{Cl} 1.41-2.28)$. Factors associated with needing more information about prostate cancer's effects on a spouse/relationship included being 75 years or older ( $\mathrm{OR}=0.62,95 \% \mathrm{Cl}$ 0.40-0.96), non-white ( $\mathrm{OR}=2.46,95 \% \mathrm{Cl} 1.76-3.44)$, married $(\mathrm{OR}=2.64,95 \% \mathrm{Cl} 1.74-4.02)$, and having high sexual burden (OR=2.05; 95\% Cl 1.542.72). Last, we found that being non-white $(\mathrm{OR}=1.43,95 \% \mathrm{Cl} 1.04-1.96)$, undergoing a combination of treatments for prostate cancer ( $\mathrm{OR}=1.63,95 \% \mathrm{Cl} 1.26-2.12)$, having a recurrence $(\mathrm{OR}=1.53 ; 95 \% \mathrm{Cl} 1.03-2.28)$, having high sexual burden $(\mathrm{OR}=1.60 ; 95 \% \mathrm{Cl}$ 1.23-2.07), and having high bowel burden ( $\mathrm{OR}=2.28 ; 95 \% \mathrm{Cl} 1.43-3.63)$ were all factors associated with needing more information about long term effects/recovery from prostate cancer.

This article is protected by copyright. All rights reserved 


\section{Discussion}

Using a statewide cancer registry of long-term prostate cancer survivors we found that unmet information needs are a lasting problem. The leading topics of unmet information needs related to recurrence of prostate cancer, effects on spouse/relationship, and long term effects/recovery from prostate cancer. Not surprisingly, survivors with higher symptom burden compared to those with lower symptom burden, regardless of quality of life domain, continue to need more supportive information many years after diagnosis, especially with respect to managing the longterm or late effects of prostate cancer treatment. In addition, we identified sub-groups of survivors who were particularly vulnerable to needing more information regarding their recovery and survivorship period including non-white prostate cancer survivors and those who have undergone a combination of treatments. Health care systems and providers should remain vigilant to these unmet information needs long after diagnosis and help survivors navigate towards resources to improve their quality of life. Based on our findings, outreach efforts should be tailored to survivors at greatest risk of unmet information and treatment needs (e.g., those with the greatest symptom burden).

Prostate cancer survivors need more long-term information support. Men with greater symptom burden may have greater information needs for at least two reasons. First, men with greatest symptoms may have greater unmet clinical needs due to lack of access to information. Second, men with the greatest symptom burden may not be seeking care for all their concerns, perhaps, thinking that nothing could be done to alleviate particular symptoms due to lack of information. While providers may be in tune with the need for information regarding prostate cancer recurrence, directing survivors to resources and/or help with search strategies for other concerns may be beneficial for these groups of men. For example, providers could refer survivors to sexual health counselors or online resources.

The 2014 American Cancer Society prostate cancer survivorship care guidelines call for reducing such unmet needs. Results reported here identify critical unmet needs in addition to particular sub-groups for whom targeted, tailored interventions might be warranted rather than a "one size fits all" supportive approach for the entire survivor population. (11) Our findings also suggest that using a patient-centered approach and 
identifying individuals who may be at a greater risk for reduced quality of life due to their symptom burden could be one way to tailor appropriate survivorship care. Automated symptom assessment via interactive voice response (IVR) technology is one feasible, low cost, and efficient strategy to identify prostate cancer survivors with high symptom burden. (27) Using new technologies to monitor outcomes over time and then tailor appropriate follow-up care may further improve patient-centered prostate cancer survivorship care.

This study has several limitations. First, this was a cross-sectional survey so we cannot determine causal relationships over time. However, the large sample size and extended time since diagnosis both indicate that information needs and symptom burden persist long after a cancer diagnosis. Further exploration of how symptom burden evolves in long term survivors and the subsequent impacts on changing information needs appears warranted, similar to how a changing disease state (i.e., cancer recurrence) influenced information needs as discovered in this study. While the extent to which survivors in this study were already engaged in symptom management was also not known, we continued to find high long-term symptom burden and information needs among selected patients indicating further support appears warranted. Second, the sample is limited to prostate cancer survivors in the state of Michigan. Nonetheless, there is no reason to suspect that this state-based sample would diverge from national estimates given the stable and non-trivial rates of side effects after prostate cancer treatment across all settings. While we do not have prostate cancer pathology for patients in this study to help contextualize our findings, we did capture self-reported recurrence and over half of patients were treated with surgery indicating the generalizability of our findings to current long-term survivor population. Third, our response rate was $38.3 \%$ among eligible participants; however, this is favorable compared to similar cancer survivorship studies. (28) Fourth, our symptom burden measure is based on a dichotomized measure of overall domain-specific burden. We used a sensitivity analysis to examine different cutoff values and the findings still support the conclusion that survivorship information should be tailored to symptom burden. Last, we did not prospectively test whether information needs would be better met with tailored materials. As health care systems and providers continue to 
improve automated patient-reported assessments, understanding how to tailor information to individual patients will be critical to optimizing the quality of survivorship care.

In conclusion, we found that unmet information needs are a lasting problem among long-term prostate cancer survivors. Our findings suggest that non-white race, multimodality treatment, recurrence, and high symptom burden were all significant correlates of needing more long-term supportive information in specific topic areas. Provision of information may acknowledge patient concerns and facilitate primary care clinician and specialist efforts to achieve the highest possible long-term quality of life after cancer treatment. Future research should assess the effectiveness of tailored information support for prostate cancer survivors to determine whether a personalized approach can help satisfy long-term information needs and improve overall quality of life by promoting self-management and appropriate health care utilization.

\section{Acknowledgments}

This research was supported by the National Cancer Institute of the National Institutes of Health Training in Research for Behavioral Oncology \& Cancer Control Award (R25CA117865) to Dr. Bernat, the VA HSR\&D Career Development Award - 2 (CDA 12-171) to Dr. Skolarus, and the VA HSR\&D IIR (12-116) to Drs. Skolarus and Hawley.

\section{Abbreviation key}

Interactive voice response (IVR)

Expanded Prostate Cancer Index Composite-26 (EPIC-26)

\section{References}


1. Ferlay J, Soerjomataram I, Ervik M, Dikshit R, Eser S, Mathers C, et al. GLOBOCAN 2010 v1.0, Cancer Incidence and Mortality Worldwide: IARC CancerBase No. 11 [Internet]. Lyon, France: International Agency for Research on Cancer; 2013 [cited 2015 Jun 5]. Available from: Available from: http://globocan.iarc.fr.

2. Bray F, Ren JS, Masuyer E, Ferlay J. Global estimates of cancer prevalence for 27 sites in the adult population in 2008. Int J Cancer. 2013;132(5):1133-45.

3. Resnick MJ, Koyama T, Fan KH, Albertsen PC, Goodman M, Hamilton AS, et al. Long-term functional outcomes after treatment for localized prostate cancer. The New England journal of medicine. 2013;368(5):436-45.

4. Sanda MG, Dunn RL, Michalski J, Sandler HM, Northouse L, Hembroff L, et al. Quality of Life and Satisfaction with Outcome among Prostate-Cancer Survivors. New England Journal of Medicine. 2008;358(12):1250-61.

5. Gore JL, Kwan L, Lee SP, Reiter RE, Litwin MS. Survivorship beyond convalescence: 48-month quality-of-life outcomes after treatment for localized prostate cancer. Journal of the National Cancer Institute. 2009;101(12):888-92.

6. From Cancer Patient to Cancer Survivor: Lost in Transition. Washington, DC: The National Academies Press; 2005. 536 p.

7. Cheung WY, Neville BA, Cameron DB, Cook EF, Earle CC. Comparisons of patient and physician expectations for cancer survivorship care. Journal of clinical oncology : official journal of the American Society of Clinical Oncology. 2009;27(15):2489-95.

8. Ercolano E. Follow up of men post-prostatectomy: who is responsible? Urologic nursing. 2008;28(5):370-7; discussion 8-80.

9. Saultz JW, Albedaiwi W. Interpersonal continuity of care and patient satisfaction: a critical review. Annals of family medicine. 2004;2(5):445-51.

10. Yabroff KR, Davis WW, Lamont EB, Fahey A, Topor M, Brown ML, et al. Patient time costs associated with cancer care. Journal of the National Cancer Institute. 2007;99(1):14-23.

11. Skolarus TA, Wolf AMD, Erb NL, Brooks DD, Rivers BM, Underwood W, et al. American Cancer Society prostate cancer survivorship care guidelines. CA: A Cancer Journal for Clinicians. 2014;64(4):225-49. 
12. Darwish-Yassine M, Berenji M, Wing D, Copeland G, Demers RY, Garlinghouse $\mathrm{C}$, et al. Evaluating long-term patient-centered outcomes following prostate cancer treatment: findings from the Michigan Prostate Cancer Survivor study. Journal of cancer survivorship : research and practice. 2014;8(1):121-30.

13. Hughes A, Wittmann DA. Aging Sexuality: Knowledge and Perceptions of Preparation among U.S. Primary Care Providers. Journal of Sex and Marital Therapy. Epub ahead of print (February 2014):1-10.

14. Rutten LJ, Arora NK, Bakos AD, Aziz N, Rowland J. Information needs and sources of information among cancer patients: a systematic review of research (19802003). Patient education and counseling. 2005;57(3):250-61.

15. Harrison-Woermke DE, Graydon JE. Perceived informational needs of breast cancer patients receiving radiation therapy after excisional biopsy and axillary node dissection. Cancer nursing. 1993;16(6):449-55.

16. Cawley M, Kostic J, Cappello C. Informational and psychosocial needs of women choosing conservative surgery/primary radiation for early stage breast cancer. Cancer nursing. 1990;13(2):90-4.

17. Luker KA, Beaver K, Leinster SJ, Owens RG, Degner LF, Sloan JA. The information needs of women newly diagnosed with breast cancer. J Adv Nurs. 1995;22(1):134-41.

18. Michie S, Rosebert C, Heaversedge J, Madden S, Parbhoo S. The effects of different kinds of information on women attending an out-patient breast clinic. Psychology, Health \& Medicine. 1996;1(3):285-96.

19. Meredith C, Symonds P, Webster L, Lamont D, Pyper E, Gillis CR, et al. Information needs of cancer patients in west Scotland: cross sectional survey of patients' views. BMJ (Clinical research ed). 1996;313(7059):724-6.

20. Derdiarian AK. Effects of information on recently diagnosed cancer patients' and spouses' satisfaction with care. Cancer nursing. 1989;12(5):285-92.

21. Echlin KN, Rees CE. Information needs and information-seeking behaviors of men with prostate cancer and their partners: a review of the literature. Cancer nursing. 2002;25(1):35-41. 
22. Galbraith ME, Hays L, Tanner T. What men say about surviving prostate cancer: complexities represented in a decade of comments. Clinical journal of oncology nursing. 2012;16(1):65-72.

23. Mclnnes DK, Cleary PD, Stein KD, Ding L, Mehta CC, Ayanian JZ. Perceptions of cancer-related information among cancer survivors: a report from the American Cancer Society's Studies of Cancer Survivors. Cancer. 2008;113(6):1471-9.

24. Lavery JF, Clarke VA. Prostate cancer: Patients' and spouses' coping and marital adjustment. Psychology, Health \& Medicine. 1999;4(3):289-302.

25. Heyman EN, Rosner TT. Prostate cancer: an intimate view from patients and wives. Urologic nursing. 1996;16(2):37-44.

26. Moore KN, Estey A. The early post-operative concerns of men after radical prostatectomy. J Adv Nurs. 1999;29(5):1121-9.

27. Skolarus TA, Holmes-Rovner M, Hawley ST, Dunn RL, Barr KL, Willard NR, et al. Monitoring quality of life among prostate cancer survivors: the feasibility of automated telephone assessment. Urology. 2012;80(5):1021-6.

28. Smith T, Stein KD, Mehta CC, Kaw C, Kepner JL, Buskirk T, et al. The rationale, design, and implementation of the American Cancer Society's studies of cancer survivors. Cancer. 2007;109(1):1-12.

\section{Figure legend}

Figure 1. Information need differences between prostate cancer survivors with low versus high domain-specific symptom burden. When stratifying by symptom burden level and domain, individuals with high symptom burden compared to low symptom burden were more likely to need more information on at least one of the leading topics (i.e., recurrence of prostate cancer, effects on spouse/relationship, and long term effects/recovery from cancer) regardless of the specific domain $\left({ }^{*} p<.05\right)$. 
Table 1. Characteristics of the Michigan Prostate Cancer Survivor Study population $(n=2,499)$

\begin{tabular}{|c|c|}
\hline Characteristic & $\mathrm{N}(\%)$ \\
\hline \multicolumn{2}{|l|}{$\mathrm{Age}^{\mathrm{a}}$} \\
\hline$\leq 64$ years & $342(13.8)$ \\
\hline $65-74$ years & $824(33.3)$ \\
\hline$\geq 75$ years & $1309(52.9)$ \\
\hline \multicolumn{2}{|l|}{ Race $^{\mathrm{b}}$} \\
\hline White & $1870(80.2)$ \\
\hline Non-white & $461(19.8)$ \\
\hline \multicolumn{2}{|l|}{ Education level attained $^{c}$} \\
\hline Less than high school education & $345(13.9)$ \\
\hline High school graduate or GED & $651(26.3)$ \\
\hline Some college to college graduate & $989(40.0)$ \\
\hline Some graduate school to graduate degree & $489(19.8)$ \\
\hline \multicolumn{2}{|l|}{ Marital status $^{d}$} \\
\hline Not married & $535(21.6)$ \\
\hline Married & $1938(78.4)$ \\
\hline \multicolumn{2}{|l|}{ Income $e^{e}$} \\
\hline$\leq \$ 20,000$ & $316(13.6)$ \\
\hline$\$ 20,000-34,999$ & $637(27.3)$ \\
\hline$\$ 35,000-49,999$ & $461(19.8)$ \\
\hline$\$ 50,000-74,999$ & $418(17.9)$ \\
\hline$\geq \$ 75,000$ & $498(21.4)$ \\
\hline \multicolumn{2}{|l|}{ Time since diagnosis $^{\dagger}$} \\
\hline$\leq 5$ years & $266(11.1)$ \\
\hline $5-9$ years & $983(40.9)$ \\
\hline $10-14$ years & $692(28.8)$ \\
\hline$\geq 15$ years & $465(19.3)$ \\
\hline \multicolumn{2}{|l|}{ Treatment type ${ }^{\mathrm{g}}$} \\
\hline Prostatectomy & $1207(55.1)$ \\
\hline Combination (including prostatectomy) & $982(44.9)$ \\
\hline \multicolumn{2}{|l|}{ Disease status $^{h}$} \\
\hline No recurrence & $2119(87.7)$ \\
\hline Recurrence & $297(12.3)$ \\
\hline \multicolumn{2}{|l|}{ Urinary symptom burden' } \\
\hline Low & $2077(85.6)$ \\
\hline High & $350(14.4)$ \\
\hline
\end{tabular}

This article is protected by copyright. All rights reserved 


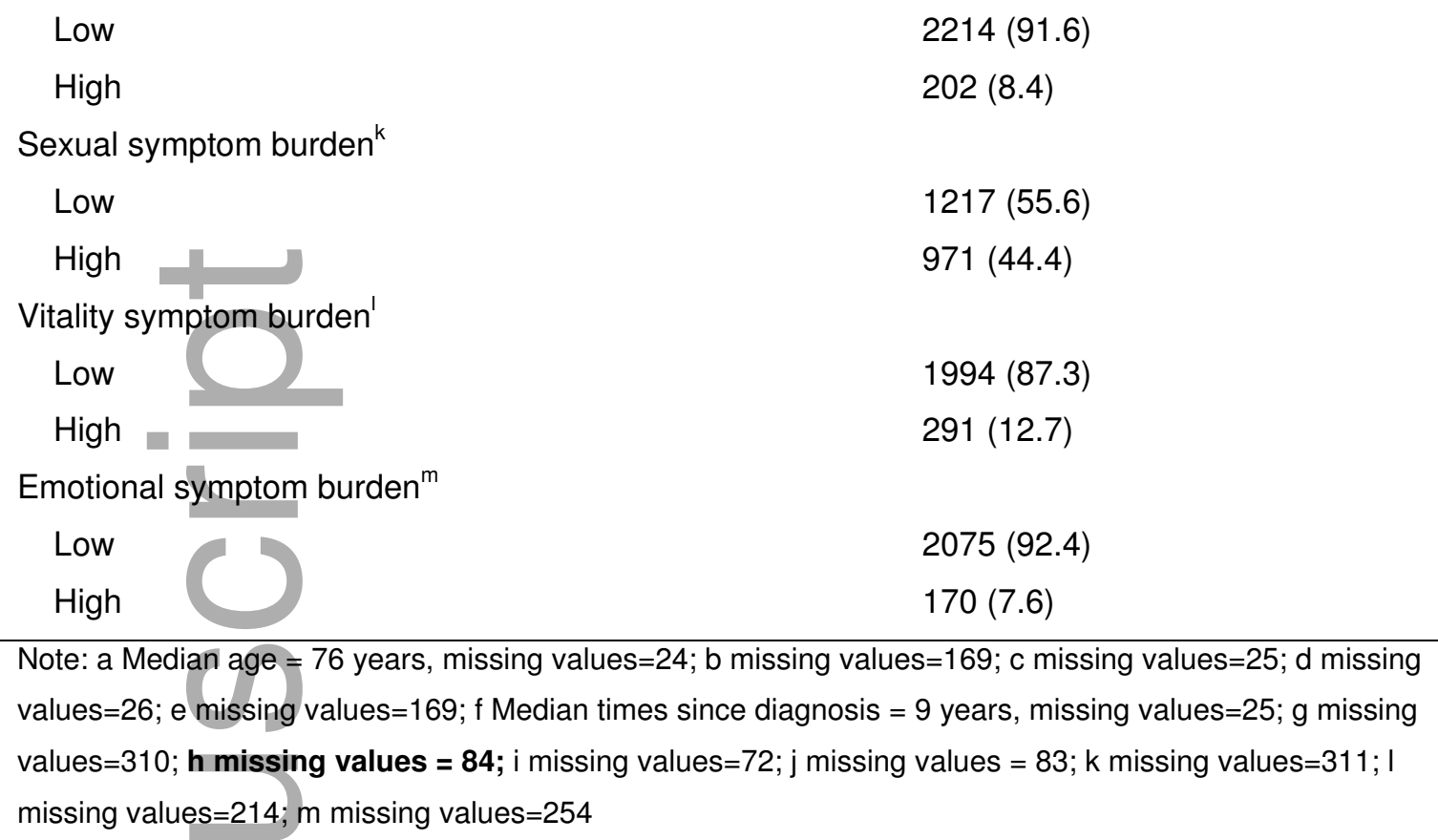

Note: a Median age $=76$ years, missing values=24; $\mathrm{b}$ missing values=169; $\mathrm{c}$ missing values=25; $\mathrm{d}$ missing values=26; e missing values $=169 ; \mathrm{f}$ Median times since diagnosis $=9$ years, missing values $=25 ; \mathrm{g}$ missing values $=310 ; \mathbf{h}$ missing values $=84 ;$ i missing values $=72 ; j$ missing values $=83 ; \mathrm{k}$ missing values $=311 ; \mathrm{I}$ missing values $=214 ; \mathrm{m}$ missing values $=254$

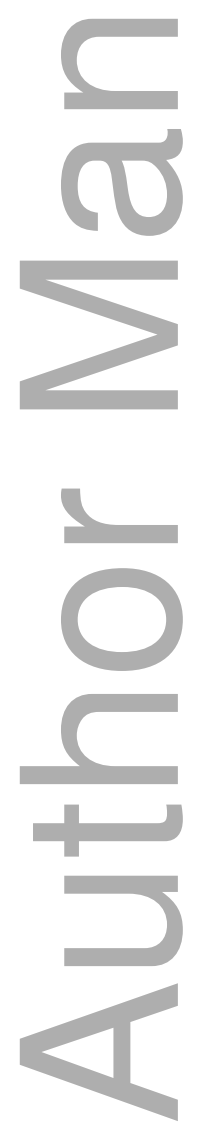


Table 2. Information need topics reported by prostate cancer survivors $(n=1,397)$

\begin{tabular}{lll} 
Information need topic & $\mathrm{N}$ & $\%$ \\
\hline Recurrence of Prostate Cancer & 776 & 55.5 \\
Effects on spouse/relationship & 701 & 50.2 \\
Long Term Effects/Recovery from Cancer & 621 & 44.5 \\
Causes of Cancer/Prevention of Cancer & 496 & 35.5 \\
General Information on Prostate Cancer & 478 & 34.2 \\
Treatment/Cures for Cancer & 451 & 32.2 \\
Symptoms of Cancer & 327 & 23.4 \\
Screening/Testing/Early Detection & 270 & 19.3 \\
Diagnosis of Cancer & 246 & 17.6 \\
Coping with Cancer/Dealing with Cancer & 234 & 16.8 \\
Alternative/Home Remedies & 158 & 11.3 \\
Paying for Medical Care/Insurance & 144 & 10.3 \\
Where to Get Medical Care & 128 & 9.1 \\
Cancer Organizations & 77 & 5.5 \\
Other & 68 & 4.9 \\
\hline Not Mulipla
\end{tabular}

Note: Multiple answers given; Excludes those who said 'None' to needing more complete information on prostate cancer

This article is protected by copyright. All rights reserved 
Table 3. Factors associated with information needs in long-term prostate cancer survivors $(n=2,499)$

\begin{tabular}{|c|c|c|c|c|c|c|c|c|c|}
\hline Information Needs & \multicolumn{3}{|c|}{ Recurrence } & \multicolumn{3}{|c|}{ Effects on spouse/relationship } & \multicolumn{3}{|c|}{ Long-term effects/Recovery } \\
\hline Factors & $\mathrm{OR}^{1}$ & $95 \% \mathrm{Cl}$ & $p$ & OR & $95 \% \mathrm{Cl}$ & $p$ & OR & $95 \% \mathrm{Cl}$ & $p$ \\
\hline \multicolumn{10}{|l|}{ Age $^{-}$} \\
\hline$\leq 64$ years & ref & & & ref & & & ref & & \\
\hline $65-74$ years & 1.22 & $0.85-1.73$ & 0.28 & 0.91 & $0.62-1.34$ & 0.64 & 0.92 & $0.64-1.33$ & 0.67 \\
\hline$\geq 75$ years & 1.05 & $0.72-1.54$ & 0.80 & 0.62 & $0.40-0.96$ & 0.03 & 0.72 & $0.48-1.08$ & 0.11 \\
\hline \multicolumn{10}{|l|}{ Race } \\
\hline White & ref & & & ref & & & ref & & \\
\hline Non-white & 1.36 & $1.00-1.85$ & 0.05 & 2.46 & $1.76-3.44$ & 0.00 & 1.43 & $1.04-1.96$ & 0.03 \\
\hline \multicolumn{10}{|l|}{ Marital Status } \\
\hline Not married & ref & & & ref & & & ref & & \\
\hline Married & 0.97 & $0.72-1.33$ & 0.87 & 2.64 & $1.74-4.02$ & 0.00 & 1.01 & $0.72-1.40$ & 0.97 \\
\hline \multicolumn{10}{|l|}{ Income } \\
\hline$\leq \$ 20,000$ & ref & & & ref & & & ref & & \\
\hline$\$ 20,000-34,999$ & 1.31 & $0.83-2.07$ & 0.25 & 1.48 & $0.84-2.59$ & 0.17 & 0.94 & $0.58-1.52$ & 0.80 \\
\hline$\$ 35,000-49,999$ & 1.44 & $0.89-2.33$ & 0.14 & 1.52 & $0.85-2.72$ & 0.16 & 1.08 & $0.65-1.80$ & 0.76 \\
\hline$\$ 50,000-74,999$ & 1.40 & $0.85-2.32$ & 0.19 & 1.15 & $0.63-2.12$ & 0.65 & 0.99 & $0.58-1.68$ & 0.96 \\
\hline$\geq \$ 75,000$ & 1.72 & $1.03-2.87$ & 0.04 & 1.38 & $0.74-2.56$ & 0.32 & 1.26 & $0.73-2.16$ & 0.41 \\
\hline \multicolumn{10}{|l|}{ Treatment type } \\
\hline Prostatectomy & ref & & & ref & & & ref & & \\
\hline Combination $^{2}$ & 1.79 & $1.41-2.28$ & 0.00 & 1.09 & $0.82-1.44$ & 0.56 & 1.63 & $1.26-2.12$ & 0.00 \\
\hline \multicolumn{10}{|l|}{ Disease status } \\
\hline No recurrence & ref & & & ref & & & ref & & \\
\hline
\end{tabular}

This article is protected by copyright. All rights reserved 


\section{Recurrence}

Sexual symptom burden

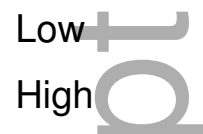

Bowel symptom burden

Low

High
$1.17 \quad 0.80-1.71$

0.42

1.23

$0.79-1.91$

0.36

1.53

$1.03-2.28$

0.04

ref

$1.13 \quad 0.88-1.44 \quad 0.33$

ref

2.05

$1.54-2.72$

0.00

ref

ref

$0.88 \quad 0.56-1.40 \quad 0.60$

$\begin{array}{llll}1.15 & 0.68-1.95 & 0.61 & 2.28\end{array}$

ref

$\begin{array}{lll}1.60 & 1.23-2.07 & 0.00\end{array}$

ref

$2.28 \quad 1.43-3.63 \quad 0.001$

Note: ${ }^{1}$ Adjusted odds ratios. We controlled for the following additional covariates: education, time since diagnosis, and urinary, vitality and emotional symptom burden levels. ${ }^{2}$ Includes a combination of treatments (e.g., radical prostatectomy, external radiation, hormone replacement therapy).

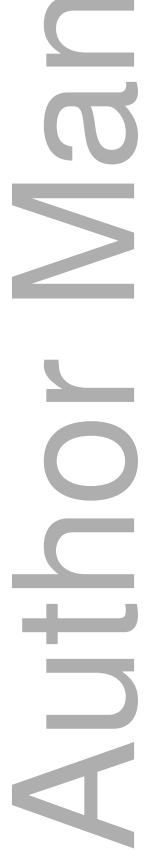

This article is protected by copyright. All rights reserved 
Figure 1. Information need differences between prostate cancer survivors with low versus high domain-specific symptom burden.
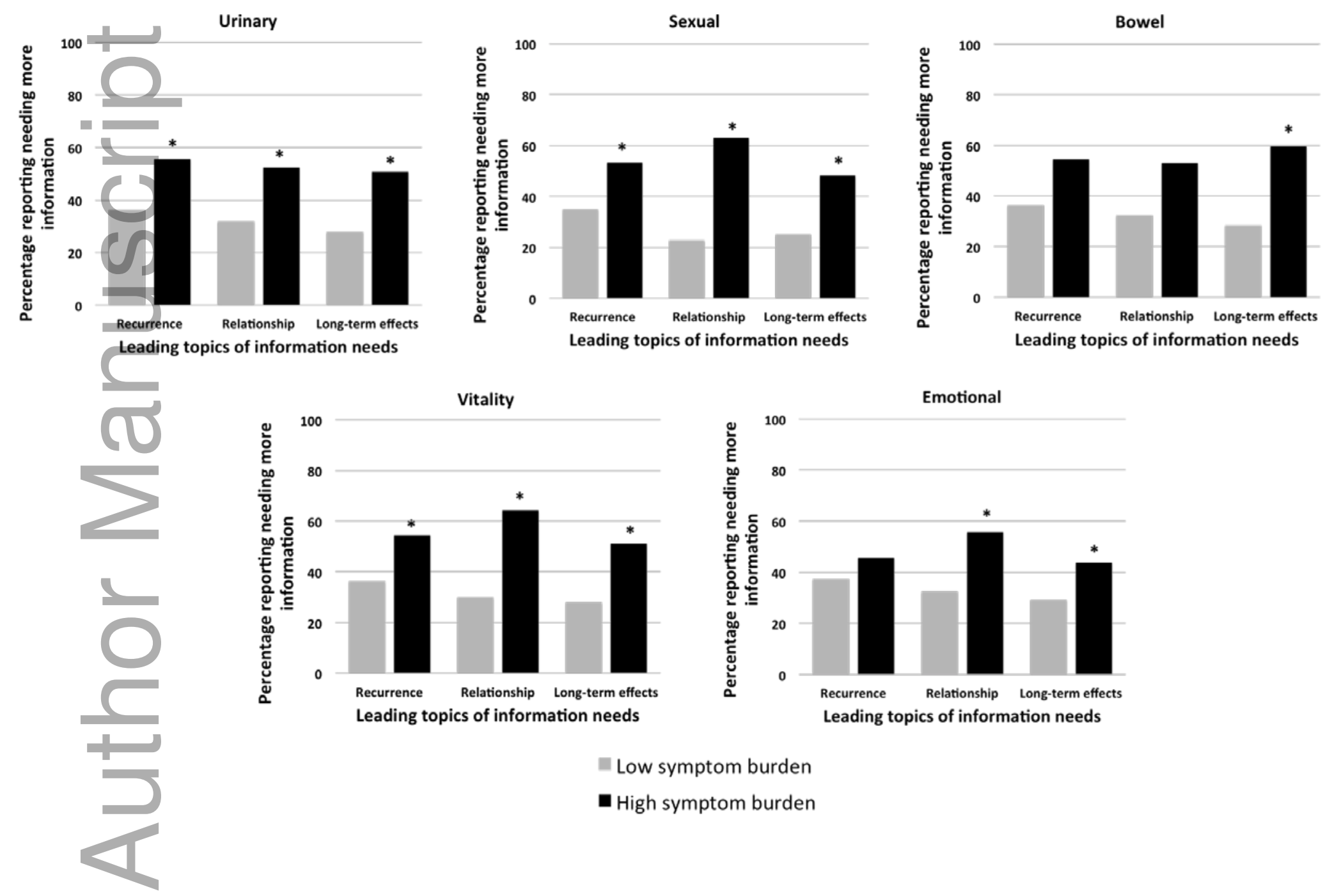

This article is protected by copyright. All rights reserved 